\title{
IX. Observations on the solar eclipse, November 29th, 1826
}

\section{Rev. Baden Powell M.A. F.R.S.}

To cite this article: Rev. Baden Powell M.A. F.R.S. (1827) IX. Observations on the solar eclipse, November 29th, 1826, Philosophical Magazine Series 2, 1:1, 28-31, DOI: 10.1080/14786442708674201

To link to this article: http://dx.doi.org/10.1080/14786442708674201

曲 Published online: 10 Jul 2009.

Submit your article to this journal $₫$

Џ Article views: 2

Q View related articles $₫$ 
minated on groups of milky white opaque felspar, most of the crystals of which are covered with a thin dark uron black coating, and mica in large laminæ. These crystals offer only two varieties; one of which is represented by fig. 2 , and the other differs from it by the absence of the planes $b_{\frac{1}{2}} *$.

They generally present both summits. The planes $m$ and $b^{1}$ are very brilliant, the planes $b_{\frac{1}{2}}$ and $b^{\frac{t}{3}}$ dull, and the planes $g^{1}$ slightly undulated and of a highly vitreous lustre. Their colour varies from grayish white to a deep brown. Some are transparent; others only transluscent or opaque. Some of the crystals are as large as a wallnut, generally much smaller, but very well defined.

Fig. 2.

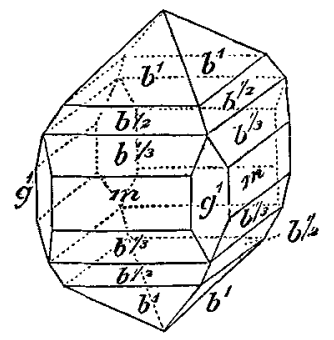

IX. Observations on the Solar Eclipse, November 29th, 1826. By the Rev. Baden Powell, M.A. F.R.S.

\section{To the Editors of the Philosophical Magazine and Annals of} Philosophy.

THE curious observations of Mr. Wiseman during the solar eclipse of September 1820, recorded in the Memoirs of the Astronomical Society (Part I. p. 140.) tend to show that during the eclipse there was a deficiency of the red rays of the sun and the heating power accompanying them. 'This conclusion is considered to be corroborated by the further observation of a diminution in the space occupied by the red rays in the prismatic spectrum formed at the same time. The facts are stated to have been anticipated by Mr. Wiseman; but the principle on which he anticipated them is not mentioned.

As there is nothing said in the paper alluded to, which can lead us to determine how far the effects may depend upon the magnitude of the eclipse, it will be dbubtless a point of interest, not only on the occurrence of an eclipse of equal magnitude to verify the facts; but also in other cases to ascertain whether, or in what degree, similar effects are produced.

With this object in view, I made a few observations during the eclipse of November 29th. The weather was favourable only for one short interval in the early part of the eclipse,

* Since writing the above, I have observed another variety which besides the modifications of fig. 2 . presents the planes, which Haüy has designated by $x$. 
and again for a longer period towards its termination. My observations were made on the top of a house in the city :-unfavourable, however, as the circumstances were, I believe the results, as far as they go, can be relied on.

I adopted a somewhat different method from that used by Mr. W.; and one which appears to me capable of giving more accurate results. It consists in having two thermometers, the bulb of one painted red, the other black: these being fixed on one mounting with their bulbs detached, and exposed together to the influence of the sun's rays when eclipsed, and when in its ordinary state, any difference in the quantity of red rays and of their heating power, in the two cases, would be shown by a difference in the ratio of the risings of the two thermometers in a given time upon exposure to the sun. The thermometers were graduated to quarters of centigrade degrees, and the diameters of their bulbs were, red 0.6 inch; black 0.55 inch.

The following is a statement of the results I was enabled to obtain. The thermometers were held at a distance from surrounding objects, and were as much as possible screened from the wind, but not perfectly.

Nov. 29.

A.M. $10^{\text {h }} 25^{\mathrm{m}}$ : Clouds cleared off. Eclipse considerable.

\begin{tabular}{|c|c|c|c|}
\hline \multirow[t]{2}{*}{ Minutes. } & \multicolumn{2}{|c|}{$\begin{array}{l}\text { Rise upon exposure to } \\
\text { the Sun. }\end{array}$} & \multirow{2}{*}{ Ratio. } \\
\hline & Red therm & Black therm. & \\
\hline 1 & centigr. & - & \\
\hline 2 & $0^{0.25}$ & $0^{0.5}$ & $1: 2$ \\
\hline$\dddot{6}$ & $\cdot 5$ & $1 \cdot$ & $1: 2$ \\
\hline \multicolumn{4}{|c|}{ Mean 1:2 } \\
\hline
\end{tabular}

$10^{\mathrm{h}} 45^{\mathrm{m}}$. Thick clouds.

$11^{\mathrm{h}} 20^{\mathrm{m}}$. Clouds cleared off. Eclipse considerable.

\begin{tabular}{|c|c|c|c|}
\hline $\begin{array}{l}1 \\
2 \\
3\end{array}$ & $\begin{array}{l}\cdot 25 \\
\cdot 5 \\
\cdot 75\end{array}$ & ${ }_{1 \cdot}^{\cdot 5}$ & $\begin{array}{l:l}1: 2 \\
1: 1.5 \\
1: 1 \cdot 3\end{array}$ \\
\hline & & \multicolumn{2}{|c|}{ Mean $1: 1 \cdot 6$} \\
\hline
\end{tabular}


A.M. $11^{\text {th }} 40^{\mathrm{m}}$. Eclipse diminished.

\begin{tabular}{|c|c|c|c|}
\hline \multirow[t]{2}{*}{ Minutes. } & \multicolumn{2}{|c|}{$\begin{array}{c}\text { Rise upon exposure to } \\
\text { the Sun. }\end{array}$} & Ratio. \\
\hline & Red therm. & Black therm & red. : black. \\
\hline 1 & .25 & $\cdot 5$ & $1: 2$ \\
\hline 2 & $\cdot 5$ & $1 \cdot 25$ & $1: 2 \cdot 3$ \\
\hline 3 & $\cdot 5$ & $1 \cdot 5$ & $1: 3$ \\
\hline \multicolumn{3}{|c|}{$1: 2 \cdot 4$} & $1: 2 \cdot 4$ \\
\hline
\end{tabular}

$11^{\mathrm{h}} 50^{\mathrm{m}}$. Eclipse very small.

\begin{tabular}{|l|l|l|l|}
\hline 1 & $\begin{array}{l}\cdot 5 \\
2\end{array}$ & $\begin{array}{l}1 \cdot 25 \\
2 \cdot\end{array}$ & $\begin{array}{l}1: 2.5 \\
1: 2\end{array}$ \\
\hline
\end{tabular}

$12^{\mathrm{h}} 5^{\mathrm{m}}$. After eclipse ended.

\begin{tabular}{|c|c|c|c|}
\hline $\begin{array}{l}1 \\
2 \\
3\end{array}$ & $\begin{array}{l}\cdot 25 \\
\cdot 5 \\
1 \cdot\end{array}$ & $\begin{array}{c}\cdot 5 \\
\cdot 75 \\
1.5\end{array}$ & $\begin{array}{l:l}1: 2 \\
1: 1.5 \\
1: 1.5\end{array}$ \\
\hline & & Me & $1: 1 \cdot 6$ \\
\hline
\end{tabular}

The results of these different observations exhibit some discrepancy, which may probably be attributed to the varying influence of wind, occasional haziness, \&cc.; but if those obtained during the eclipse be compared with those when there was none, I conceive no such difference will appear as can be supposed connected with the circumstance of the eclipse.

From these results we may infer, that during the present eclipse, (viz. one of about $6 \frac{1}{2}$ digits, ) the rays underwent no such modification as was sufficient to produce a perceptible difference in the ratio of the effects on a red and a black thermometer.

From Mr. Wiseman's statement respecting the alteration which took place in the spectrum, I conceive it will be desirable to verify by the more perfect methods now known, of insulating homogeneous rays, whether in such an eclipse any given ray is either entirely wanting, or very much weakened. 
So far as the case of the present eclipse bears upon the question, I tried this with respect to the extreme red rays discovered by Mr. Herschel, to which the greatest heating power belongs; and looking at the sun during the eclipse through a good prism of flint glass, interposing before the eye three thicknesses of the purple glass, described by that gentleman, I saw the ray in question perfectly distinct, and unaltered as compared with its appearance when there was no eclipse.

The deep red image of the sun thus forming the end of the spectrum, of course exhibited the eclipse; and in a spectrum formed in a darkened room, if the superposition was but small, the same deficiency at the red end might be apparent; but this obviously would not explain a deficiency of heat as compared with that of the compound rays; nor would it account for the increased brilliancy which Mr. Wiseman observed in the yellow and blue.

I am not aware what was the cause reasoned upon by $\mathrm{Mr}$. W. as capable of producing any actual relative deficiency of red rays: if it were any such cause as inflexion of the sun's light in passing the body of the moon, which should affect the red rays most, and thus the light reaching the earth should be deprived of a portion of red, a less portion of green, blue, \&c. this would produce a diminution in intensity, though not a deficiency in space, in the red part of the spectrum. Hence, however, would result a greater relative brightness in the blue, \&c.; and such a difference in the heating effects as has been described. Such a cause would act more sensibly in porportion to the magnitude of the eclipse; and its effects might be quite insensible, except in a very considerable eclipse.

X. The Bakerian Lecture. On the Relations of Electrical and Chemical Changes. By Sir Humphry Davy, Bart. Pres. R.S.*

\section{Introduction.}

A LONG time has elapsed since I read before this Society A the Bakerian Lecture on the Chemical Agencies of Electricity. The general laws of decomposition developed in that paper were immediately illustrated by some practical results, which the Society did me the honour to receive in a very favourable manner; and which, by offering a class of new and powerful agents, led me away for many years into a field of

* From the Philosophical Transactions for 1826. Part III. 